Provided for non-commercial research and educational use only. Not for reproduction or distribution or commercial use

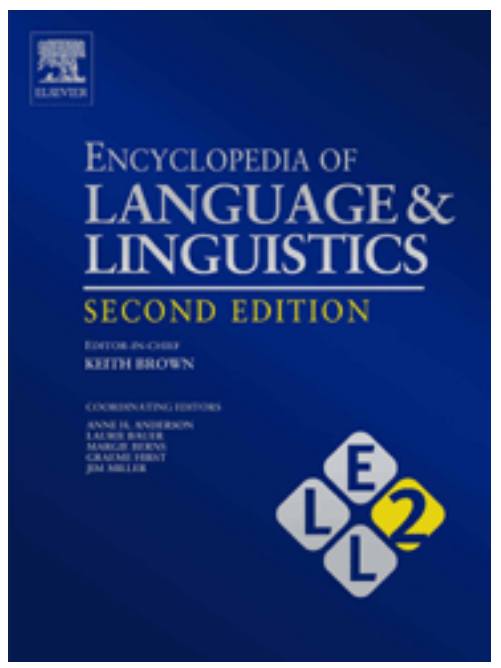

This article was originally published in the Encyclopedia of Language \& Linguistics, Second Edition, published by Elsevier, and the attached copy is provided by Elsevier for the author's benefit and for the benefit of the author's institution, for noncommercial research and educational use including without limitation use in instruction at your institution, sending it to specific colleagues who you know, and providing a copy to your institution's administrator.

All other uses, reproduction and distribution, including without limitation commercial reprints, selling or licensing copies or access, or posting on open internet sites, your personal or institution's website or repository, are prohibited. For exceptions, permission may be sought for such use through Elsevier's permissions site at:

\title{
http://www.elsevier.com/locate/permissionusematerial
}

Cornips L (2006), Variation and Formal Theories of Syntax, Chomskyan. In: Keith Brown, (Editor-in-Chief) Encyclopedia of Language \& Linguistics, Second Edition, volume 13, pp. 330-332. Oxford: Elsevier. 


\section{Variation and Formal Theories of Syntax, Chomskyan}

L Cornips, Royal Netherlands Academy of Arts and Sciences, Amsterdam, The Netherlands

(c) 2006 Elsevier Ltd. All rights reserved.

\section{Variable Rule/Linguistic Variable}

In the 1960s both sociolinguistic and formal syntax models contained formal rules that could be applied obligatorily or optionally. Formal rules in the earliest Chomskyan transformational model were transformations that connected deep structures with surface structures on the basis of rewrite rules. Optional rules, for example, derived passive, negative, or question sentences from declarative sentences. Labov introduced the concept of variable rule as an extension of this optional rule to include social and stylistic, i.e., external dimensions of language use along with linguistic, i.e., internal dimensions. There is some confusion about the notion of the variable rule since in the earliest literature it refers to both a theoretical model of how to analyze and account for language variation as well as to a method of statistical analysis (Cedergren and Sankoff, 1974). However, both paradigms soon followed their own avenues: the successive transformational models assumed the existence of categorical rules only while variationist sociolinguistics has maintained the notion of the optional rule. The two perspectives on the nature of formal rules reflect deep-seated differences between the two models. The variationist ideas are that the output of a linguistic rule can be probabilistic rather than discrete, and that a linguistic constraint can have a quantitative rather than deterministic effect on the outcome of the process. Formal syntax, however, postulates a blind, deterministic application of a series of procedures given a certain starting point (Chomsky, 1995).

Labov has modified the generative model with the variable rule as a means to accommodate interspeaker and intraspeaker variation. The variationist sociolinguistic practice that has evolved from studies of language variation and change since then takes the principle of accountability as basic (cf, Sankoff, 1990: 296). This principle states that the variants belonging to the same syntactic variable must be specified by the total number of occurrences and the potential occurrences or nonoccurrences in the variable environment, i.e., it ranges between $0 \%$ and $100 \%$. It guarantees that the entire range of variability present in the data will be dealt with. The principle of accountability inevitably follows the synonymy principle. This principle is the prerequisite for variants to be assigned to the same linguistic variable: only syntactic variants that are equivocal with regard to referential meaning, i.e., variants that are 'alternate ways of saying "the same" thing,' belong to the same variable. In practice, the assignment of meaning or function of syntactic variants is considered as problematic (Lavandera, 1978).

The indeterminacy of synonymy/functional equivalence is considered not so problematic when examining the phenomenon of verbal agreement, which is present in many vernacular dialects of English all around the world (cf. King, 1994 for French varieties in Canada), as illustrated in (1):

(1a) We parch it (cf. Poplack and Tagliamonte, z1989: 49)

(1b) We parches the coffee

and copula variability, as in African-American Vernacular English (AAVE) (Rickford et al., 1991) or creole varieties, illustrated in (2):

(2a) I am just telling the boys (cf. Weldon, 2003:43)

(2b) I'm gonna get me a blue tag

(2c) I feel like I Ø fourteen

The examples above illustrate that two or more forms of functional category such as number agreement in (1) and tense in (2) are considered to belong to one linguistic variable. Other linguistic variables that can be found in variationist sociolinguistic practice over the last fifteen years in journals such as Language Variation and Change and Journal of Sociolinguistics include, for example, null versus overt subjects in varieties of Spanish (Cameron, 1993) and Bislama (Meyerhoff, 2000), particles in Japanese (Takano, 1998) and Mandarin Chinese (Shi, 1989), null versus overt objects in Hungarian (Kontra, 2001), double objects in Dutch (Cornips, 1998), relativization strategies in English varieties and AAVE (Tottie and Rey, 1997), and negation in Scots English (Smith, 2001).

Furthermore, these studies examine nonstandard rather than standard varieties and they may differ considerably in the frequency of the tokens collected, which may range from 29 (Cornips, 1998) to 6809 (Tagliamonte, 1998). It appears that both a low and high frequency of (morpho)syntactic variables may reveal significant correlations between the use of linguistic variants and social dimensions in the speech community. 


\section{Structural Representation of the Syntactic Variants}

In addition to the synonymy principle, the notion of the linguistic variable as a structural unit was also based on the assumption that the variants have an identical underlying structure or representation, which is subject to variable surface realizations (Winford, 1996: 177). So the alternation between active and passive examples was considered to be instances of different surface manifestations of the same underlying or deep structure. Santorini (1993) and Pintzuk (1995) are examples of studies within the government and binding framework where it was argued that different word orders such as SOV and VSO are derived by movement. However, in later generative models, the idea of a derivational model was abandoned in favor of a configurational model (most recently Minimalism), in which a single representation is subject to various constraints. An example is the study of Meechan and Foley (1994), where variable verbal number agreement in existentials was analyzed as a reflection of different configurational positions of the postverbal NP (a second example is Meyerhoff, 2000).

As a consequence, the original notion of the linguistic variable as a structural unit such that syntactic variants are different surface realizations of an underlying structure has been lost too. The consequences are that the syntactic variable as a structural unit has to be defined again depending on the particular model of syntax one employs. Other studies that can be mentioned in the older principles and parameters framework are Henry (1995) and Cornips (1998), where variants constituting the linguistic variable were brought about by different properties of functional categories. Since the consecutive models in generative grammar follow each other at rather high speed, different makeups of the structural unit can be detected in recent decades.

\section{An Overall Theory of Grammar and the Locus of Variability}

Many researchers claim that a bridge between variation and theory remains possible; that is, it is assumed that there exists a fairly direct connection between grammar and language usage. The organization of the grammar may be reflected in the patterns of usage (Taylor, 1994) or quantitative results may lend strong support to structural analysis (Pintzuk, 1995). Or, to put it differently, through the use of variationist methodology and knowledge about the factors contributing to syntactic variation, one catches "a glimpse of grammatical structure" (Meechan and Foley, 1994: 82). Wilson and Henry (1998: 8) phrased the advantages of an overall theory of grammar including variation and formal theory as follows: "We may be able better to understand language variation and change as they are driven by social factors but constrained (at one level) by the nature of possible grammars." One problematic issue in this socially realistic account is how to account for the fact that individual speakers can use several variants of the syntactic variable when maintaining the same style level. This issue is related to the questions within the successive generative models about the locus of syntactic variation, and its restrictions and predictions. In the literature, two alternative approaches to this 'choice' have been suggested (Muysken, 2005). Either the 'choice' is put outside the grammatical mechanisms (Kroch, 1989; Adger and Smith, 2005), or it is put inside the grammar by re-introducing optional rules (Wilson and Henry, 1998; Henry, 2002). The first option was advocated by Kroch and his associates, who claimed that grammar is a blind, autonomous system and the notion of 'choice' (optionality, variability) is not part of it. Instead, the individual speaker revealing variability has separate or competing grammars. Adger and Smith (2005) also argued that the notion of 'choice' cannot be accounted for within the autonomous grammar. In contrast with Kroch's vision, this does not imply that individual speakers "have different grammars, per se, but rather a range of lexical items open to them, some of which will have syntactic effects." In their analysis, the notion of 'choice' concerned the level that serves as the input for the autonomous grammatical system. However, Henry (1995) argued that individual grammars include variability and, consequently, the speaker has a real choice in terms of syntactic operations, for instance, optional verb movement. However, all agreed that an analysis of language use (quantitative analysis, intraand interspeaker variation) in addition to formal theory, i.e., the study of both internal and external constraints, has the potential not only to assess but also to refine theoretical conceptions of linguistic structure.

See also: Binding Theory; Chomsky, Noam (b. 1928); Constant Rate Hypothesis; Copula Variation; Functional Categories; Labov, William (b. 1927); Microparametric Variation; Principles and Parameters Framework of Generative Grammar; Syntactic Constructions; Syntactic Variables and Variable-free Syntax; Syntactic Variation; Weinreich, Uriel (1926-1967); X-Bar Theory. 


\section{Bibliography}

Adger D \& Smith J (2005). 'Variation and the minimalist program.' In Cornips \& Corrigan (eds.).

Cameron R (1993). 'Ambiguous agreement, functional compensation, and nonspecific tú in the Spanish of San Juan, Puerto Rico, and Madrid, Spain.' Language Variation and Change 5, 305-334.

Cedergren H \& Sankoff D (1974). 'Variable rules: performance as a statistical reflection of competence.' Language 50, 333-355.

Chomsky N (1995). The minimalist program. Cambridge, MA: MIT Press.

Cornips L (1998). 'Syntactic variation, parameters and their social distribution.' Language Variation and Change 10(1), 1-21.

Cornips L \& Corrigan K (2005). 'Convergence and divergence in grammar.' In Auer P, Hinskens F \& Kerswill P (eds.) Dialect change: convergence and divergence in European languages. Cambridge: Cambridge University Press.

Cornips L \& Corrigan K (eds.) (2005). Biolinguistic and sociolinguistic accounts of syntactic variation: doubts about dichotomy. Amsterdam/Philadelphia: John Benjamins.

Cornips L \& Corrigan K (eds.) (2005). Syntax and variation. Reconciling the biological and the social. Current Issues in Linguistic Theory. Amsterdam/Philadelphia: John Benjamins.

Henry A (1995). Belfast English and standard English: dialect variation and parameter setting. Oxford: Oxford University Press.

Henry A (2002). 'Variation and syntactic theory.' In Chambers J, Trudgill P \& Schilling-Estes N (eds.) The Handbook of Language Variation and Change. Oxford: Blackwell. 267-282.

King R (1994). 'Subject-verb agreement in Newfoundland French.' Language Variation and Change 6, 239-253.

Kontra M (2001). 'Hungarian verbal puzzles and the intensity of contact.' Journal of Sociolinguistics 5(2), 163-179.

Kroch A (1989). 'Reflexes of grammar in patterns of language change.' Language Variation and Change 1, 199-244.

Labov W (1994). Principles of linguistic change: internal factors. Oxford: Blackwell.

Lavandera B (1978). 'Where does the sociolinguistic variable stop?' Language in Society 7, 171-182.

Meechan M \& Foley M (1994). 'On resolving disagreement: linguistic theory and variation - There's bridges.' Language Variation and Change 6, 83-85.
Meyerhoff M (2000). 'The emergence of creole subjectverb agreement and the licensing of null subjects.' Language Variation and Change 12, 203-230.

Muysken P (2005). 'A modular approach to sociolinguistic variation in syntax: the gerund in Ecuadorian Spanish.' In Cornips \& Corrigan (eds.).

Pintzuk S (1995). 'Variation and change in Old English clause structure.' Language Variation and Change 7, 229-260.

Poplack S \& Tagliamonte S (1989). 'There's no tense like the present.' Language Variation and Change 1, 47-84.

Rickford J R, Ball A, Blake R, Jackson R \& Martin N (1991). 'Rappin on the copuls coffin: theoretical and methodological issues in the analysis of copula variation in African-American Vernacular English.' Language Variation and Change 3, 103-132.

Sankoff G (1990). 'The grammaticalization of tense and aspect in Tok Pisin and Sranan.' Language Variation and Change 2, 295-312.

Santorini B (1993). 'The rate of phrase structure change in the history of Yiddish.' Language Variation and Change 5, 257-283.

Shi Z (1989). 'The grammaticalization of the particle le in Mandarin Chinese.' Language Variation and Change 1, 99-114.

Smith J (2001). 'Negative concord in the old and new world: evidence from Scotland.' Language Variation and Change 13, 109-134.

Tagliamonte S (1998). 'Was/were variation across the generations: view from the city of York.' Language Variation and Change 10, 153-191.

Takano S (1998). 'A quantitative study of gender differences in the ellipsis of the Japanese postpositional particles - wa and - $g a$ : Gender composition as a constraint on variability.' Language Variation and Change 10, 289-323.

Taylor A (1994). 'The change from SOV to SVO in ancient Greek.' Language Variation and Change 6, 1-37.

Tottie G \& Rey M (1997). 'Relativization strategies in earlier African American Vernacular English.' Language Variation and Change 9, 219-247.

Weldon T L (2003). 'Copula variability in Gullah.' Language Variation and Change 15, 37-72.

Wilson J \& Henry A (1998). 'Parameter setting within socially realistic linguistics.' Language in Society 27, $1-21$.

Winford D (1996). 'The problem of syntactic variation.' In Arnold J, Blake R, Davidson B, Schwenter S \& Solomon J (eds.) Sociolinguistic variation: data, theory and analysis. Stanford, CA: CSLI. 177-192. 